\title{
GRAND WATUDODOL UNDERWATER COASTAL CLEANUP
}

\author{
Sulistiono, Diah Etika Maharatih Setiarina, Nadya Adharani, \\ dan Megandhi Gusti Wardhana \\ Universitas PGRI Banyuwangi \\ Email: stio.yono@gmail.com
}

\begin{abstract}
ABSTRAK
Pantai Grand Watudodol Banyuwangi memiliki potensi alami yaitu terumbu karang dan biota-biota asosiasnya yang masih cukup bagus. Keindahan pemandangan taman bawah laut tersebut harus dijaga dari berbagai jenis sampah. Sampah-sampah yang ada di terumbu karang Grand Watudodol berasal dari sampah-sampah yang hanyut dari sungai terbawa ke muara sampai ke pantai. Untuk menjaga kebersihan terumbu karang maka masyarakat sekitar pantai harus menjaga kebersihan pantai Grand Watudodol secara rutin agar dapat memuaskan wisatawan. Tahapan-tahapan Grand Watudodol underwater coasatal cleanup yaitu dengan membagi tiga area yaitu area yang terendam air, area yang berbatasan dengan air dan area yang sama sekali tidak terendah air. Hasi bersih pantai didapatkan sampah organik dan sampah anorganik yang sebagian besar adalah kiriman dari luar bukan dari wisatawan pantai tersebut.
\end{abstract}

Kata kunci: Pantai, Grand Watudodol, Banyuwangi, Wisata Bahari, underwater coastal cleanup

\section{PENDAHULUAN}

Pariwisata menurut UNESCO (2009) adalah aktivitas perjalanan yang dilakukan untuk sementara waktu dari tempat tinggal semula ke daerah tujuan dengan alasan bukan untuk menetap atau mencari nafkah melainkanhanya untuk bersenang-senang, memenuhi rasa ingin tahu, menghabiskan waktu libur serta tujuan-tujuan lainnya. Sedangkan menurut UU No. 10 tahun 2009 tentang kepariwisataan, yang dimaksud pariwisata adalah berbagai macam kegiatan wisata dan didukung oleh berbagai fasilias serta layanan yang disediakan masyarakat, pengusaha, pemerintah, dan pemerintah daerah.

Menurut Fandeli (2000) ekowisata telah berkembang sejak tahun 2000 an dan wisata ini tidak hanya sekedar untuk melakukan pengamatan burung, mengendarai kuda, penelusuran jejak hutan belantara, tetapi telah terkait dengan konsep pelestarian hutan dan penduduk lokal. Ekowisata ini kemudian merupakan suatu perpaduan dari berbagai minat yang tumbuh dari keprihatinan terhadap lingkungan, ekonomi dan sosial. Ekowisata tidak dapat dipisahkan dengan konservasi. Oleh karenanya, ekowisata disebut juga sebagai bentuk perjalanan wisata bertanggungjawab.

Ekowisata lebih popular dan banyak dipergunakan dibanding dengan terjemahan yang seharusnya dari istilah ecotourism, yaitu ekoturisme. Terjemahan yang seharusnya dari ecotourism adalah wisata ekologi (Fandeli, 2000). Menurut UNESCO (2009) bahwa ekowisata di Indonesia sudah dicanangkan sejak tahun 2002 melalui berbagai workshop dan diskusi yang diselenggarakan pada tahun tersebut di berbagai daerah di Indonesia baik oleh pemerintah pusat atau daerah. Dari hasil workshop tersebut dirumuskan lima prinsip dasar pengembangan ekowisata di Indonesia, yaitu: 1) Pelestarian, 2) Pendidikan, 3) Pariwisata, 4) Perekonomian, 5) Partisipasi masyarakat setempat.

Salah satu contoh praktek ekowisata di Indonesia di antaranya adalah ekowisata di 
hutan bakau di Sanur Bali. Lokasi tersebut merupakan kawasan hutan bakau yang menawarkan paket ekowisata kepada pengunjung. Aktivitas trekking, pengamatan burung, naik sampan dan penanaman bakau merupakan tawaran yang diberikan kepada pengunjung. Pengunjung juga dapat mengadopsi bakau (UNESCO, 2009).

Terumbu karang adalah invertebrata yang hidup dalam bentuk koloni dan berkerabat dekat dengan ubur-ubur dan anemon laut. Terumbu karang terbuat dari individu yang sangat kecil disebut polyps. setiap polyp mengekstrak kalsium karbonat dari bagian dasar tubuhnya. Deposit kalsium karbonat yang terkumpul tersebut menjadi terumbu karang yang sering kita lihat di pantai. Terumbu karang dibagi menjadi 2 jenis yaitu karang batu (keras) dan karang lunak. Karang batu memiliki kalsium karbonat sehingga mereka dapat membentuk terumbu karang sedangkan karang lunak tidak memiliki kalsium karbonat sehingga tidak dapat membentuk terumbu karang (Veron, 2000 dan Miththapala 2008).

Terumbu karang adalah salah satu ekosistem tertua yang secara ekonomi dan biologi sangat penting di dunia. Meskipun demikian, terumbu karang menghadapi sejumlah ancaman serius, termasuk polusi dari daratan, dampak pemancingan, perubahan iklim, dan penipisan terumbu, peningkatan keasaman laut, serta kurangnya kesadaran masyarakat (NOAA, 2009). Menurut Yusnita (2014) perilaku kontak wisatawan snorkling berpengaruh nyata terhadap kerusakan terumbu karang di perairan Karimunjawa. Adanya penambahan fasilitas mooring buoy, pengarahan prasnorkling, serta manajemen pemanfaatan kawasan perairan yang baik merupakan upaya konservasi untuk menurunkan kerusakan terumbu karang di daerah wisata bahari.

Pantai Grand Watudodol merupakan pantai yang memiliki potensi alami yang terdiri dari berbagai jenis terumbu karang beserta biota-biota yang hidup di sekitarnya. Kondisi terumbu karang pantai Grand Watudodol sendiri berdasarkan studi pendahuluan masih cukup bagus. Selain itu biota-biota lain yang hidup di teurmbu karang diantaranya adalah penyu sisik, bintang laut, ikan-ikan hias karang, dan kipas laut. Kondisi tersebut merupakan daya tarik utama bagi wisatawan bahari domestik maupun mancanegara.

Informasi jenis-jenis terumbu karang, penyu, ikan, dan biota-biota lain yang hidup di sekitar terumbu karang sangat penting diketahui oleh pemandu wisata lokal dari Pantai Grand Watudodol itu sendiri agar dapat memberikan pemahaman kepada wisatawan yang datang ke Pantai Grand Watudodol. Selain informasi tersebut pemandu lokal juga harus paham kondisi ekologi yang cocok untuk pertumbuhan dan perkembangan biota-biota laut di sekitar terumbu karang. Dengan memahami kondisi ekologi tersebut maka pemandu lokal dapat menjaga lingkungan pantai agar terumbu karang dan biota-biota asosiasinya dapat hidup dengan aman dan nyaman.

Pantai Grand Watudodol Banyuwangi mendapatkan kiriman sampah hampir setiap jam dari daerah lain. Sampah-sampah tersebut lama kelamaan akan mengendap di dasar perairan dan menutupi terumbu karang yang ada. Kebersihan terumbu karang merupakan syarat utama yang harus dipenuhi oleh tempat wisata agar wisatawan nyaman dan betah lama di pantai untuk menikmatih keindahan terumbu karang yang ada. Masyarakat sekitar Pantai Grand Watudodol selayaknya melaksanakan bersih pantai secara rutin agar sampah-sampah yang ada tidak menumpuk di pantai.

Kegiatan Pengabdian ini bertujuan untuk mengajarkan kepada masyarakat sekitar Pantai Grand Watudodol Banyuwangi untuk dapat selalu menjaga kebersihan pantai secara rutin dan mengajarkan metode bersih 
pantai yang tepat kepada masyarakat sekitar Pantai Grand Watudodol Banyuwangi

Keindahan terumbu karang dan biotabiota asosiasnya merupakan target utama dan pertama para diver/snorkler domestik maupun mancanegara sehingga perlu dijaga kelestariannya. Pendidikan kesadaran lingkungan perlu diberikan kepada kelompok masyarakat pengawas Pantai Grand Watudodol.

Luaran dari pengabdian ini adalah metode yang tepat yang dapat diterapkan oleh masyarakat sekitar Pantai Grand Watudodol Banyuwangi untuk bersih pantai secara rutin. Rencana target capaian penelitian disajikan pada Tabel 1.

Tabel 1. Rencana Target Capaian

\begin{tabular}{clll}
\hline No. & \multicolumn{2}{c}{ Jenis Luaran } & \multicolumn{1}{c}{ Indikator Capaian } \\
\hline 1. & Jadwal rutin bersih & $\begin{array}{l}\text { Pantai Grand Watudodol bersih dari sampah organik maupun } \\
\text { anorganik }\end{array}$ \\
pantai & $\begin{array}{l}\text { Metode Bersih Pantai } \\
\text { yang tepat }\end{array}$ & $\begin{array}{l}\text { Area yang dibersihkan mulai dari daerah terendam air } \\
\text { sampai daerah yang tidak pernah terendam air }\end{array}$ \\
\hline
\end{tabular}

\section{METODE PENGABDIAN}

Pengabdian kepada masyarakat diawali dengan tahapan area pembersihan sampah dibagi menjadi tiga area yaitu: a) area yang terendam air pantai, b) area yang kadang-kadang terendam air pantai, c) area yang tidak pernah terendam air pantai. Selanjutnya peserta bersih pantai dibagi menjadi tiga kelompok yaitu kelompok hiu yang membersihkan sampah di pantai yang selalu terendam air, kelompok penyu yang membersihkan sampah di pantai yang tidak terendam air dan kelompok kerang yang membersihkan pantai yang sama sekali tidak pernah terendam air. Sampah yang dikumpulkan oleh kelompok hiu diserahkan ke kelompok penyu kemudian ke kelompok kerang dan akhirnya dikumpulkan di tempat ppembuangan sementara. Sampah yang sudah terkumpul di tempat pembuangan sementara diangkut oleh motor sampah dan dibuang ke tempat pembuangan akhir. Hasil sampah dipilah menjadi sampah organik dan sampah anorganik. Hasil akhir jenis-jenis sampah disosialisasikan ke masyarakat sekitar Pantai Grand Watudodol.

$$
\text { Kegiatan pengabdian kepada }
$$

masyarakat Grand Watudodol Coastal Underwater Cleanup diikuti oleh mahasiswa Teknologi Hasil Perikanan, Biologi,
Teknologi Hasil Pertanian dan beberapa dosen dari Bahasa Inggris Universitas PGRI Banyuwangi (Uniba). Selain dari Uniba, kegiatan ini juga diikuti oleh Camat Kecamatan Wongsorejo, Kasatpol air, Dinas Pariwisata, Dinas Perikanan, dan Polsek Wongsorejo.

\section{HASIL PENGABDIAN}

Hasil kegiatan pengabdian Grand Watudodol Underwater Coastal Cleanup adalah bersihnya lingkungan Pantai Grand Watudodol Banyuwangi mulai dari pantai yang selalu terendam air sampai pantai yang tidak pernah terendam air. Karena kegiatan tersebut masyarakat sekitar pantai menjadikan kegiatan bersih pantai sebagai kegiatan yang rutin dilaksanakan setiap hari jumat dan hari senin. Kegiatan bersih pantai pada hari senin adalah untuk mempersiapkan tempat yang bersih untuk wisatawan dan kegiatan bersih pantai pada hari senin dimaksudkan untuk membersihkan sampahsampah yang tertinggal oleh wisatawan yang datang ke Pantai Grand Watudodol. Kegiatan pencangkokan cemara juga dilaksanakan untuk menambah jumlah pohon cemara udang yang ada di pantai tersebut untuk memperindah pantai di kemudian hari. Kegiatan pencangkokan dilaksanakan oleh beberapa mahasiswa Uniba. 
Selain bersih pantai dan pencangkokan cemara udang, kami juga memajang beberapa tulisan-tulisan berisikan pesan untuk menjaga lingkungan pantai agar tetap bersih. Di setiap papan pesan yang kami pasang, kami sertakan label Program Studi Perikanan Uniba sebagai media promosi Uniba. Kegiatan bersih pantai yang sudah dilaksanakan mendapatkan apresiasi yang sangat besar oleh warga sekitar pantai dan dinas-dinas terkait. Dari kegiatan tersebut muncul ide kegiatan berikutnya yaitu pendataan terumbu karang di Pantai Grand Watudodol Banyuwangi.

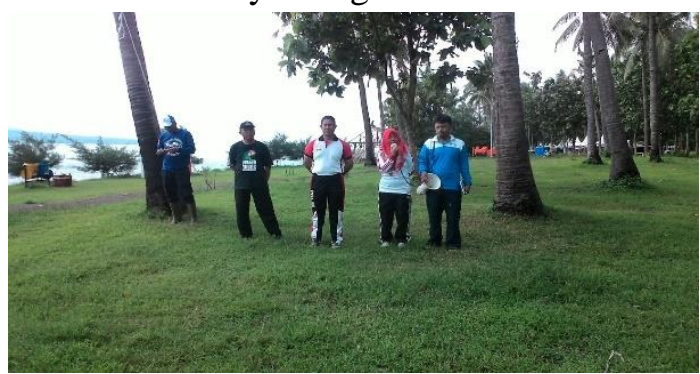

Gambar 1. Pengarahan Kegiatan Grand Watudodol Underwater Coastal Cleanup

Keterangan: dari kiri ke kanan adalah: Abdul Azis (Ketua Pokmaswas Pesona Bahari GWD), Pak Soni dari Dinas Pariwisata Banyuwangi, Kapolsek Wongsorejo, Camat Kecamatan Wongsorejo, Koordinator Kegitan GWD dari Uniba

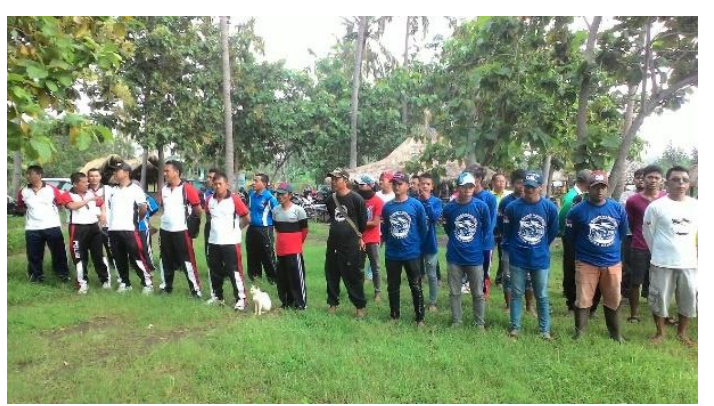

Gambar 2. Upacara Pembukaan Kegiatan Grand Watudodol Under-water Coastal Cleanup

Keterangan: peserta kegiatan (dari kiri ke kanan) adalah: Polsek Wongsorejo, PokMasWas Pesona Bahari,Uniba, Polairud, Dinas Perikanan Banyuwangi, Dinas Pariwisata.

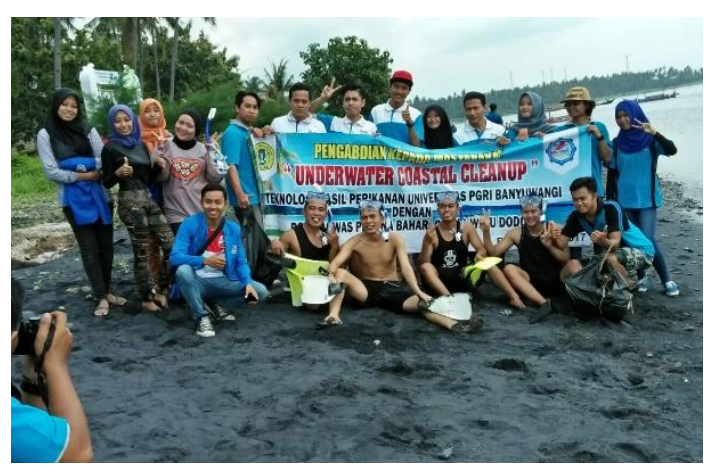

Gambar 3. Foto Bersama Peserta Grand Watudodol Underwater Coastal Cleanup

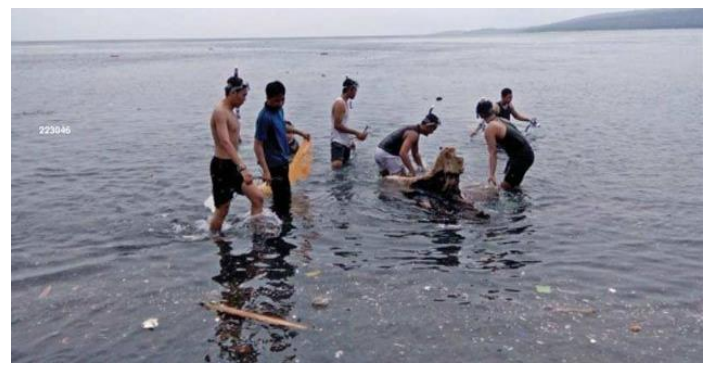

Gambar 4. Liputan Radar Banyuwangi (Sumber:

http://www.kabarbanyuwangi.info/warga-fokusdi-pantai-mahasiswa-punguti-yangmengambang.html)

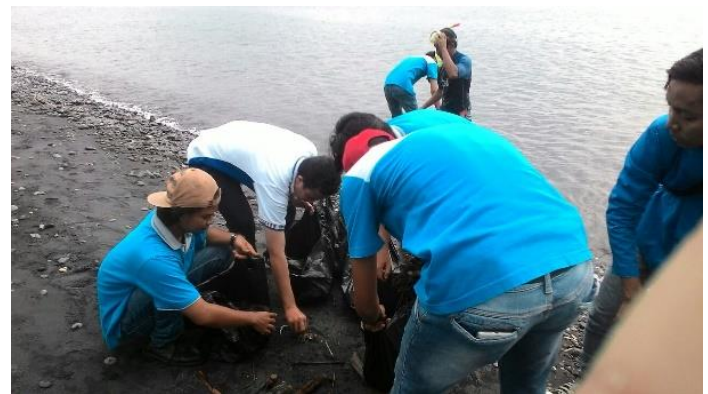

Gambar 5. Mahasiswa membersihkan sampah yang ada di bibir pantai

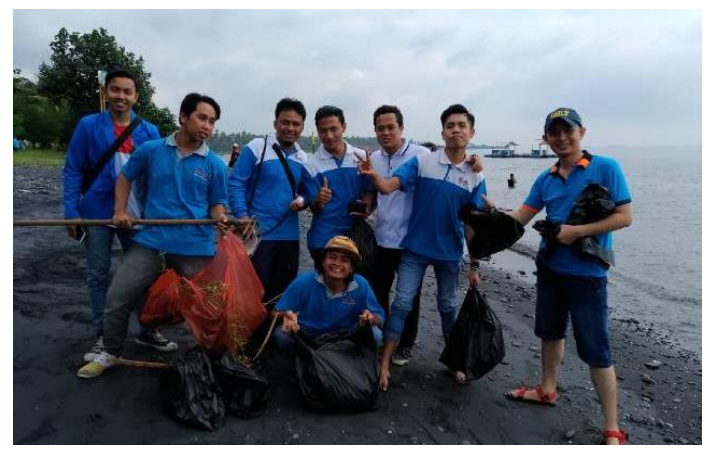

Gambar 6. Tim Bersih Sampah di Bibir Pantai 


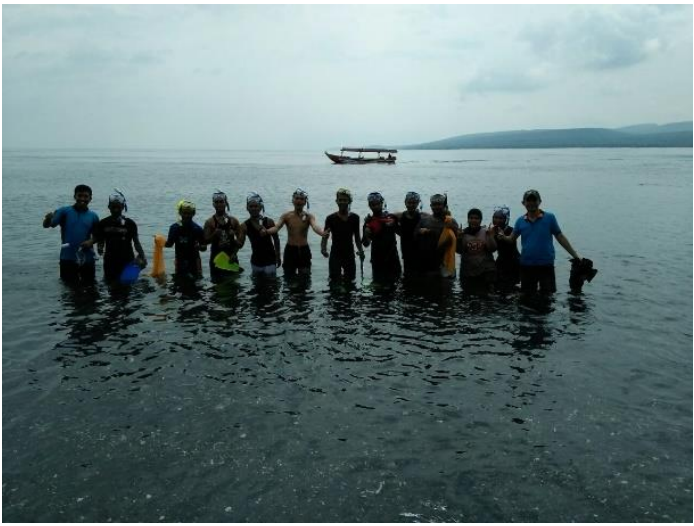

Gambar 7. Tim Hiu yang membersihkan sampah di dalam air yang menutupi terumbu karang

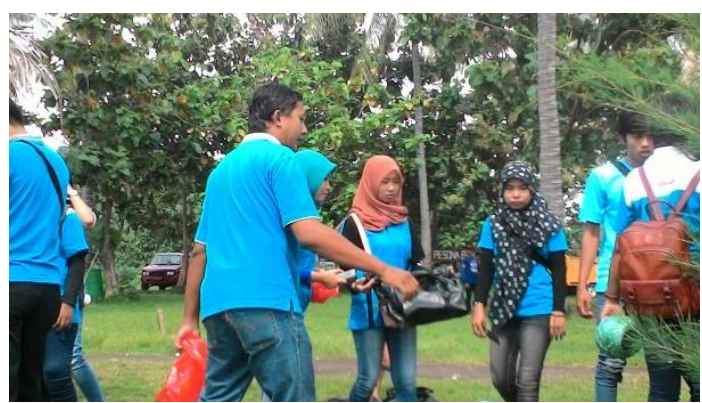

Gambar 8. Tim Lamun bertugas mencangkok pohon cemara udang

\section{KESIMPULAN}

1. Dari kegiatan pengabdian ini, masyarakat Grand Watudodol Khususnya Kelompok Masyarakat Pengawas (Pokmaswas) Pesona Bahari membuat kegiatan rutin bersih pantai mulai dari daerah yang selalu terendam air sampai daerah yang tidak pernah terendam air setiap Hari Jumat dan Senin.

2. Sampah-sampah yang ada di Pantai Grand Watudodol berupa sampah kiriman dari daerah lain.

\section{DAFTAR PUSTAKA}

Fandeli, Chafid. 2000. Pengertian dan Konsep Dasar Ekowisata. Fakultas Kehutanan. Universitas Gadjah Mada, Yogyakarta

Menteri Hukum dan Hak Asasi Manusia Republik Indonesia. 2009. UndangUndang Republik Indonesia Nomor 10 Tahun 2009 Tentang Kepariwisataan, Jakarta

Miththapala, S. 2008. Coral Reef. Coastal Ecosystems Series (Vol 1) pp 1-36+iii. Colombo, Sri Lanka: Ecosystem and Livelihoods Group Asia, IUCN

NOAA. 2009. Terumbu Karang: Melindungi Harta Karun Alam. www.noaa.gov.

Saleh. 2009. Teknik Pengukuran dan Analisis Kondisi Ekosistem Terumbu Karang. www.coremap.or.id, Jakarta

Unesco. 2009. EKOWISATA Panduan Dasar Pelaksanaan, Jakarta

Veron, JEN. 2000. Coral of the World. Marine Science

Yusnita, Ika. 2014. Kajian Potensi Dampak Wisata Bahari Terhadap Terumbu Karang di Kelurahan Pulau Panggang, Kepulauan Seribu. Institut Pertanian Bogor, Bogor 